\title{
Urban Lifecycle Management: System Architecture Applied to the Conception and Monitoring of Smart Cities
}

\author{
Claude Rochet ${ }^{1,}$ Florence Pinot de Villechenon ${ }^{2}$ \\ ${ }^{1}$ Professeur des universités \\ Aix Marseille Université \\ IMPGT AMU CERGAM EA 4225 \\ ESCP Europe Paris \\ Claude.rochet@univ-amu.fr \\ ${ }^{2}$ Directeur CERALE Centre d'Etudes et de \\ Recherche Amérique latine Europe \\ ESCP Europe Paris \\ pinot@escpeurope.eu
}

\begin{abstract}
At date, there is no standardized definition of what a smart city is, in spite many apply to propose a definition that fit with their offer, subsuming the whole of the city in one of its functions (smart grid, smart mobility...). Considering the smart cities as an ecosystem, that is to say a city that has systemic autopoeitic properties that are more than the sum of its parts, we develop an approach of modeling the smartness of the city. To understand how the city may behave as a sustainable ecosystem, we need a framework to design the interactions of the city subsystems. First we define a smart city as an ecosystem that is more than the sum of its parts, where sustainability is maintained through the interactions of urban functions. Second, we present a methodology to sustain the development over time of this ecosystem: Urban Lifecycle Management. Third, we define the tasks to be carried out by an integrator of the functions that constitute the smart city, we assume public administration has to play this role. Fourth, we present what should be a smart government for the smart city and the new capabilities to be developed.
\end{abstract}

\section{Introduction}

At date, there is no standardized definition of what a smart city is, in spite many apply to propose a definition that fit with their offer, subsuming the whole of the city in one of its functions (smart grid, smart mobility...). First we define a smart city as an ecosystem that is more than the sum of its parts, where sustainability is maintained through the interactions of urban functions. Second, we present a methodology to sustain the development over time of this ecosystem: Urban Lifecycle Management. Third, we define the tasks to be carried out by an integrator of the functions that constitute the smart city, we assume public administration has to play this role. 
Fourth, we present what should be a smart government for the smart city and the new capabilities to be developed.

This paper is based on case studies carried out within the cluster Advancity (France) for the urban ecosystem issue, and other case studies on the intention to design new business models based on the concept of extended enterprise and extended administration. It relies on the state of the art in complex system architecture as developed in information system and system engineering in complex products such as aircrafts, to envisage how these competencies may be adapted to public services in their collaborative work with private firms.

\section{What is an urban ecosystem?}

A smart city is more than the sum of "smarties" (smart grids, smart buildings, smart computing...) but there is not, at the present time, a precise and operational definition of what a smart city is (Lizaroiu \& Roscia, 2012). Several pretenders exist on what a smart city could be (Songdo in Korea, Masdar in Abu Dhabi,...) but they are not cities to live in, they are demonstrators, propelled by big companies (e.g. Cisco in Songdo) who apply a particular technology to the conception of a city.

In the literature, the smart city is recently defined as an ecosystem, that is to say a system where the whole is more than the sum of the parts and has autopoeitic properties (Neirotti et a., 2013).

For the systems architect this approach implies:

- Defining a perimeter that comprehends all the components that have a critical impact on city life: the city needs to be fed, imports products that may have been manufactured on a basis that does not fit with sustainable development requirements (pollution, children work or underpaid workers, carbon emissions...). These costs and environmental impact must be charged to the city balance.

- Considering the system as a living system where the behavior of inhabitants determines the sustainability of the ecosystemic properties of the city. The underlying assumptions are material systems in addition to immaterial ones as history, culture, anthropology and social capital - play their role. A recent trend in the literature on development economics, which is contrary to the fad of mainstream economics that consider all territories alike, put the emphasis on the "smart territory" as an unstructured cluster of tradition, culture, and informal institutions able to shape an innovative milieu (Aydalot, 1986).

If the city is an ecosystem, according to the laws of general system theory (Ashby, 1962) it may be represented as shown in figure 1:

A) It has a finality made of strategic vision borne by stakeholders (public and economic actors), people living in the city and sustaining this finality through theirs activities, and preserves its identity by interactions with its environment. 
B) This system may be broken down in tree structures of subsystems: the functions. These functions belong to hard and soft domains. Hard domains include energy, water, waste, transport, environment, buildings, and healthcare infrastructures. Soft domains include education, welfare, social capital, public administration, work, civic activity and economy. What makes the city intelligent is the richness of connections between branches. We speak of a tree structure here in the sense of Herbert Simon's architecture of complex systems (1969) where the designer will connect the subsystems to make the system emerge according to the aim it pursues. In his seminal paper "a city is not a tree" (1965) Christopher Alexander, an architect initially trained as mathematician and Professor at Berkeley, criticized the conception of the urban planning movement in America, considering it as a "fight against complexity", with no connections between branches. Modern cities conceived for cars, compared to ancient cities, offer a very poor web of connections. Alexander formalized his idea of the city conceived as a rich overlapping of building blocks in his 1977 book A pattern language. This insight of considering the whole as a combination of modular and reusable building blocks lingered on the margins of architecture but has had an enormous influence in the development of object oriented architecture in software design.

C) These functions are operated using tools and artifacts of which end-users are people, specialized workers and ordinary citizens. The critical point is that people must not fit the tools but, on the contrary, tools and artifacts will fit to people only if the right societal and institutional conditions are met.

Modeling the ecosystem implies answering three questions (Krob, 2009):

- The first question is WHY the city: what is the raison d'etre and what are the goals of the city regarding WHO are the stakeholders and which activities will support it? Beginning with this question may avoid the drift towards a techno pushed approach relying on technological determinism, one may find in Songdo or Masdar.

- The question why is then deployed in questions WHAT: What are the function the smart city must perform to reach these goals? These functions are designed in processes grouped in subsystems aligned with the goal of the main system.

- The third set of questions concern HOW these functions will be processed by technical organs operated by the people who are the city executives and employees, and the city dwellers as end users.

The issue is not to define an ideal type of smart city since all the "fitting conditions" that make the city smart will be different according to the context, but to define modeling rules to conceive and sustain the ecosystem. 


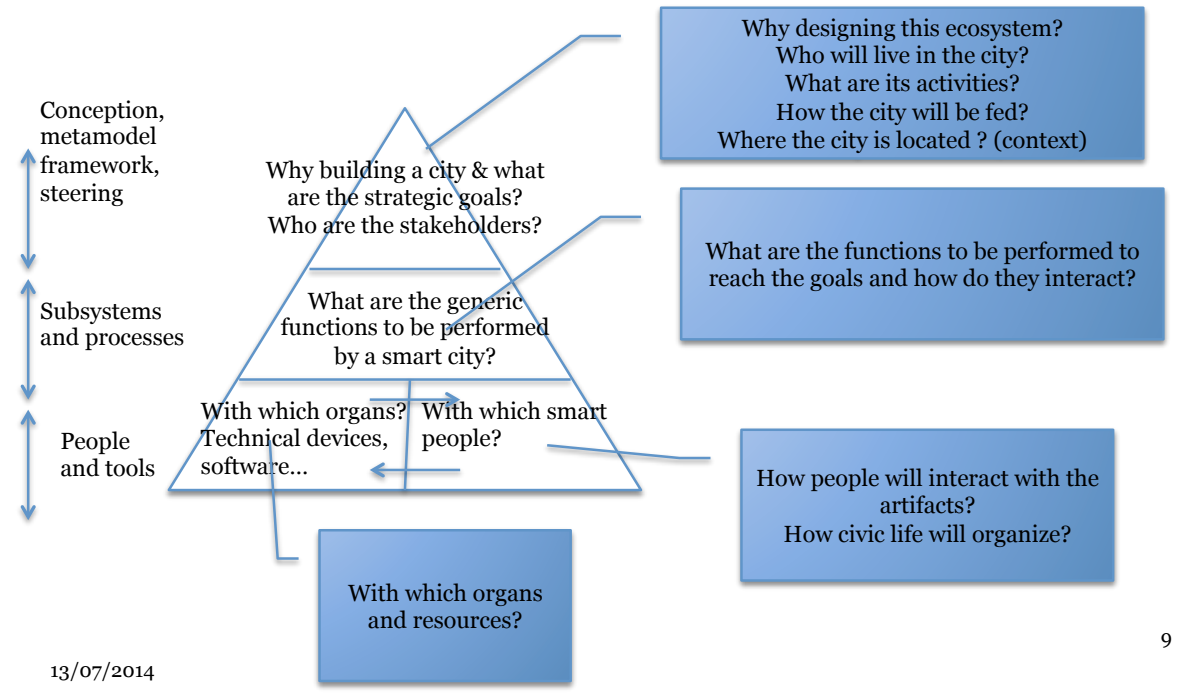

Figure 1.0: architecting the ecosystem

\section{The global framework: Urban Lifecycle Management $\left({ }^{\circ}\right.$}

Since the advent of the "death of distance" with the revolution of transportation by the middle of the $\mathrm{XIX}^{\circ}$ century, the appearance of networks of infrastructure technologies and the spread of the telegraph that transformed the government of the city, critical obstacles to the growth of cities were removed. Today digital technologies amplify this move, providing new tools such as smart phones that became a digital Swiss knife that allows inhabitants to be active actors in the city life, communicating and coordinating with each other, using and feeding databases. Doing this, digital technologies may produce the best and the worst. The point is each city contains the DNA of its own destruction. Smart cities digital infrastructure amplifies the possibilities of manifestation of discontent, worsening the gap between have and have-nots. Smart cities incur the risk to become the digital analogue of the Panopticon Jeremy Bentham's prison design (Townsend, 2013).

We assume that the rules of complex system modeling and system architecture may apply to the city as well as they apply to products through PLM (Product Lifecycle Management) in that case according to a framework we call Urban Lifecycle Management $($ C (ULM). The difference is a city never dies and must permanently renew its economic and social fabric as well as its infrastructure. An unsmart city will continuously expand according to the laws identified by G. West and L. Bettencourt (2007) that reveal an increasing return in infrastructure investment that allow the city to sprawl indefinitely. The complexity will grow out of control, resulting in a city 
being the sum of heterogeneous boroughs with strong social and economic heterogeneity and spatial dystrophy.

We define ULM first and foremost as a tool to design an ecosystem which will be coherent with the political, social and economic goal people assign to the city according to the principle of sustainable development: stability, waste recycling, low energy consumption, and controlled scalability, but in a way that allows to foresee its evolution and to monitor the transition in different ages of the city.

ULM has to counterweight the appeal of technological determinism: in the past, technologies have always dwarfed their intended design and produced a lot of unintended results. ULM has to monitor the life of the smart city alongside its evolution, as represented in figure 2.0

- A city can't be thought out of its historical and cultural context that is represented by the territory of which the city is the expression. The smart city embarks a strategic vision that is based on a strategic analysis of the context and material and immaterial assets of the territory (GREMI, 1986). The smartness of a city profoundly relies on what has been coined as "social intelligence" by prof. Stevan Dedijer in the years 1970s as the capability to build consensus where each social actor relies on others to create new knowledge. Intelligence doesn't operate in a vacuum but is socially and culturally rooted (1984).

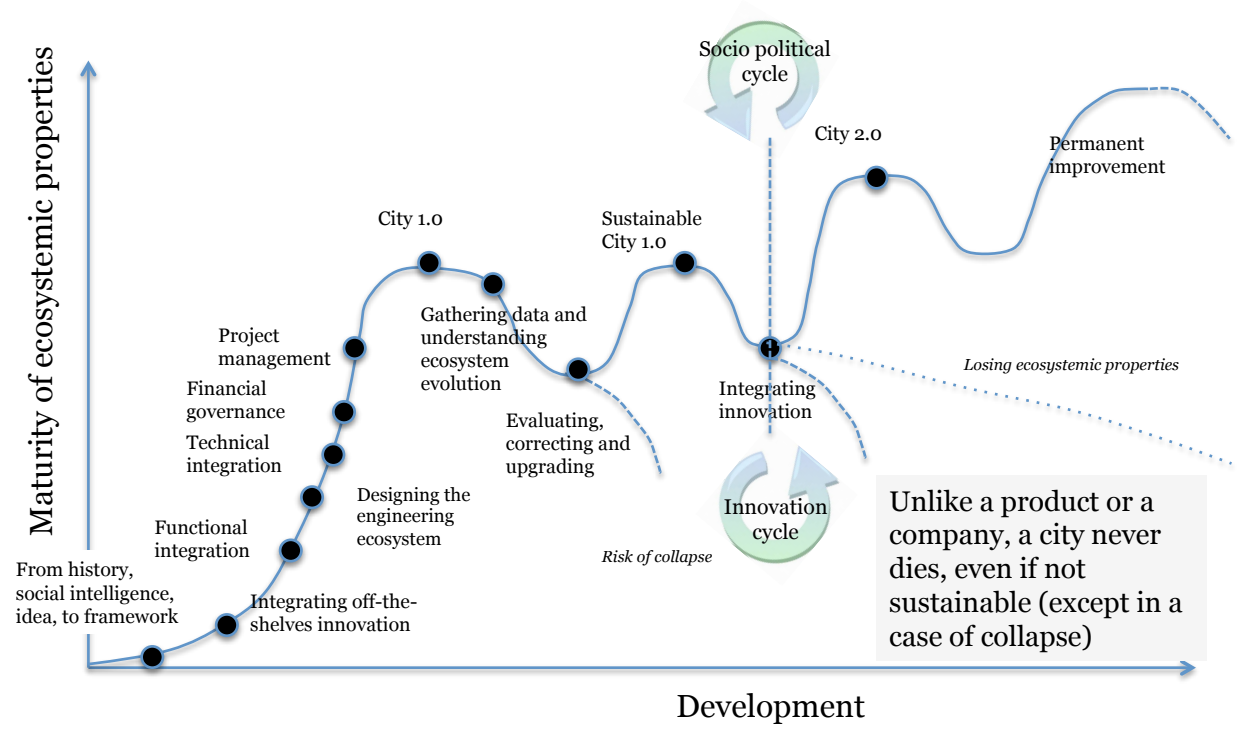

Figure 3.0: Urban Lifecycle Management $($ C

- To be livable, the city may not be a prototype city: the system architect must focus on the task of integration that needs to be reliable to proceed from offthe-shelf components that already have an industrial life and may be 
considered stable and reliable, in the same way the classical architect does not invent the brick in the same time as he designs the house. This will imply coordination between innovation cycles as we will see further.

- The process carried out on the principles represented in figure 1 leads to a first release of the city 1.0 in case of a new city. Just as well in a new or old city, we need to understand how the city lives and the unavoidable discrepancies between intended design and real result, an observatory must be implemented that will collect data produced by the city. Corrections are made according to classical principles of quality process management.

- Alongside the lifecycle, exogenous innovation will occur that will need to be endogenized by the model. For example, Songdo in his initial design relied on RFID devices to track city dwellers. Today, smart phones have become the Swiss knife of the city dwellers, rendering the use of RFID devices obsolete. Innovation is ubiquitous in all subsystems of the city. Innovation in smart cars interacts with the architecture of transportation (hard subsystem) as well as in human behavior (soft subsystem). Coordination will be needed through common frameworks such as projects management office extended to the global smart city's complexity.

- Innovation challenges the equilibrium of the smart city. Not all innovations are compulsorily good for the city: Civic and political life have to evaluate the consequences of an innovation and to frame it so that it fits with the common good and the sustainability of the city.

- All along its lifecycle, the city may lose its smartness with two undesirable consequences: the city may continue to sprawl on a non-sustainable basis leading to today clogged cities. In case of a disruption in its core activity, the city may collapsed as it happened in the past when things become too complex to be monitored, as studied for past civilizations by archeologist Joseph Tainter (1990). Reducing the size of the city is then the only solution to reduce the complexity. A similar thing appears today in Detroit, a city that has lost its goals and population, leading to the decision of reducing the size of the city as the only means of avoiding bankruptcy. A similar pattern exists with the Russian monocities.

\section{The rationale for extended public administration in the process of integration in ULM}

No two cities are alike however smart they are, but the principles of system architecture ULM are based on the assumption that common rules of modeling may be defined. One of the key rules is to understand the interactions between economic development and human capital: economic development is critical to draw financial resources for investment in new transportations, infrastructures and education. Cities with a greater economic development appear more attractive to people who wish to increase their standard of life and who are more fitted to increase the smart cities 
human capital. The more a smart city has a high level of human capital, the more she has end users able to develop, test and use new tools that improve the quality of urban life (Neirotti \& a. 2014). It is all the more true in the digital era were the end-user is not only a consumer but also a prod-user - according to the definition by sociologist Axel Burns - who is involved in a continuing process of producing never finished artifacts. On the other hand, the city has to take care to not create a digital divide.

The modeling rules consist of three main principles:

1. Strategic analysis: As represented in figure 1.0 the first task is to define the issues with the stakeholders. The functions needed to reach these issues are then defined, and deployed in organs and specific competencies and resources, as represented in figure 3.0

2. Inventorying the building blocks: There is no absolute definition of what is a smart city is and in spite we may define general rule of modeling, the definition of the smartness of a city will always be specific to the context, e.g. geographical and climate constraints (a city exposed to tropical floods or earthquake will embark functions that a city in a temperate country won't need), economic activity (specialization, search for synergies, position on the commercial routes and worldwide supply chains). The selection of these functions is essential to build a resilient city, e. g. with the climate change new phenomenon occur such as flood, marine submersion, extreme frost the city was not prepared for.

Nevertheless, common functions will exist in every city and their organization may proceed from off-the-shelf patterns.

Issues
- Defining "smartness" and
"sustainability"
- Wealth creation
- Finance and taxes
- Controlling pollution
- Equilibrium center -
periphery
- Migrations
- Poverty
- Education
- Health
- Crime
- Segregation (social and
spatial)
- Leisure
- Quality of life
- How people interact with
people and artifacts?

\begin{tabular}{|l|}
\hline \multicolumn{1}{|c|}{ Functions } \\
\hline - Work \\
- Budgeting \\
- Transportation \\
- Feeding \\
- Caring \\
- Protecting \\
- Securing \\
- Housing policy \\
- Education \\
- Leisure \\
- Social benefits \\
- Health care system \\
- Migrations control \\
\hline
\end{tabular}

\begin{tabular}{l} 
Resources \\
\hline - Energy \\
- Water \\
- Data \\
- Digital Systems \\
- Traditions \\
- Sociology \\
- Technologies as enablers \\
and enacters \\
- Culture and traditions \\
- Institutions and public \\
organizations \\
- Process modeling \\
- Software \\
- Tech providers \\
- Open innovation \\
\end{tabular}

\begin{tabular}{l} 
Capabilities \\
\hline - The New Business Models: \\
- Public \\
- Private \\
- Project management \\
- Institutional arrangements \\
- The day to day decision \\
making process in an \\
evolutionarry perspective \\
- Empowerment \\
- Direct democracy \\
- Government \\
- Governance \\
- Project management \\
- Social innovation \\
- The state as a system \\
engineer \\
- Mastering ULM \\
\hline
\end{tabular}

Figure 3.0: The building blocks 
3. Integrating the ecosystem: In complex systems dynamics, the behavior of a system as a whole is an emergence, that is to say that the property of the system can't be attributed to one function in particular but is the result of interactions between these functions. The "good life" is the basic question of political philosophy since Aristotle. It is an ethical issue that will result from political and strategic debates among the stakeholders. Jane Jacobs (1995) has criticized the utilitarian approach that prevailed in America in the city planning movement. The ancestor of the urban planning movement, Ebenezer Howard, thought of the smart city as an ideal city conceived from scratch as a mix of country and city. His insight was to conceive the city as an interaction between a city with jobs and opportunity but with pollution, and the countryside with fresh air and cheap land but with fewer opportunities, each one acting as magnets attracting and repelling people. He invented a third magnet, the Garden city, which combined the most attractive elements of both city and countryside (Howard, 1902). Garden city was the Songdo of its day (Townsend 2013) that galvanized architects, engineers and social planners in search of a rational and comprehensive approach of building city. Howard's approach was excoriated by Jane Jacobs in his Death and Life of Great American Cities (1961) for not giving room to real life: "He conceived of good planning as a series of static acts; in each case the plan must anticipate all the needed... He was uninterested in the aspects of the city that could not be abstracted to serve his utopia". In fact, the city garden dream, not relying on a global systemic architecture, has degenerated in the banal reality of suburban sprawl.

The same risk exists today with digital technologies, which could revive the ideal city dream, under the impulse of the big players such as Cisco, IBM, Siemens, GE who have interest in a top-down and deterministic approach that reduce smart cities to the adoption of their "intelligent" technology. To avoid this bias system architecture must be on the top of the agenda of extended public administration. This activity may be summed up in four points:

a) Soft and hard subsystems: Today's prototypes of would be smart cities are

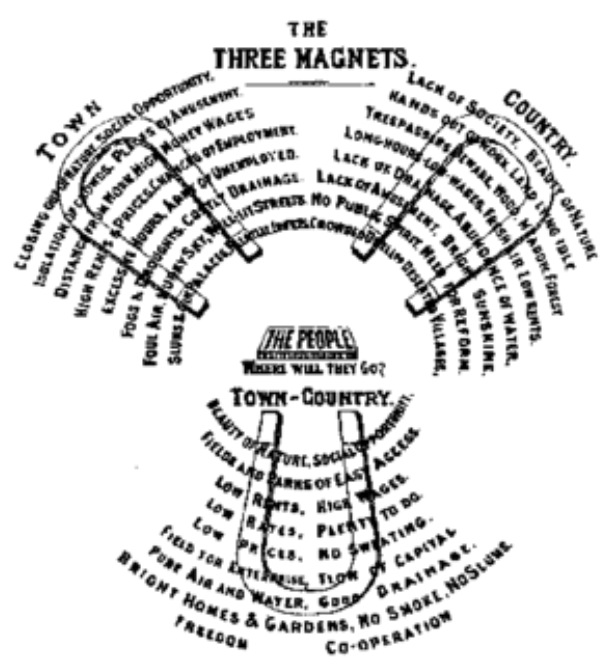
techno pushed and put emphasis on the possibilities of technology to make the city smart but mainly forget the inhabitants. City dwellers have the main role to play since it is their behavior and their use (and more and more the production) of information and technology that make the day to day decisions that render the ecosystem smart or no. Figure 4.0 represent both parts of the ecosystem the soft or human subsystem and the hard one, 
the group of technical subsystems. Integration of these subsystems obeys different laws: human subsystems are dissipative ones, difficult to model, not obeying physical laws with important entropy. Reducing their uncertainty relies on the sociology of uses, social consensus based on accepted formal and informal institutions, and a close association of inhabitants to the design of the system, which is a common feature of complex system design. Physical subsystems are conservative ones that can be modeled through the laws of physics with a possibility to reduce entropy, but keeping in mind that the decider in last resort is the city dweller who will use it.

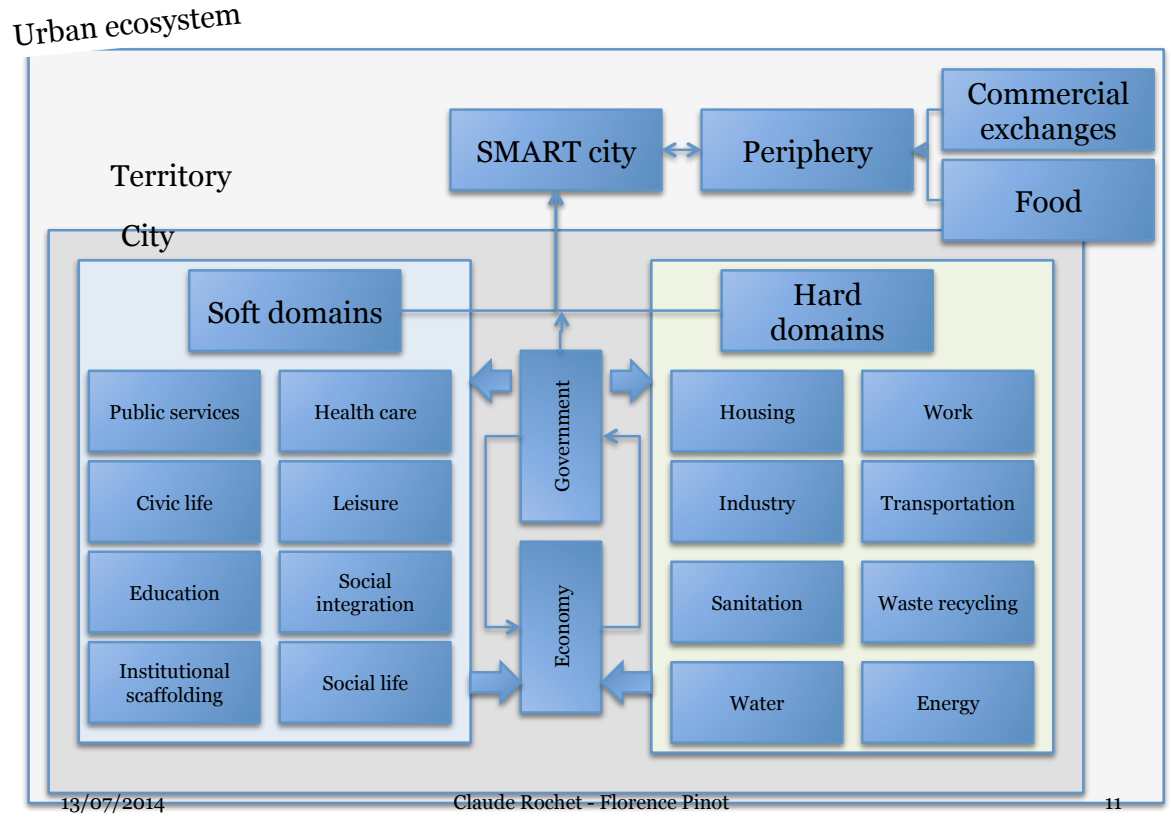

- Figure 4: The smart city as an emergence

b. Outside/inside: The urban ecosystem is not reducible to the city itself, with perhaps the exceptions of city-states as Singapore where the limits of the city are given by nature. A city must be fed and have exchanges with a close periphery which produces goods (services, agriculture, food...) in interaction with the center. The design of a system relies on the definition of the border of the system. According to the laws of complex system modeling (Ashby law) the inner complexity of a system must be appropriate to the complexity of its environment. So, the urban ecosystem will have to define three perimeters: the first is the city itself inside which the synergies and interactions are the stronger and have the most "eco" properties. The second is the periphery: one may refer here to the model defined by Thünen at the beginning of the XIX ${ }^{\circ}$ century representing the city with a succession of concentric rings going from the highest increasing return activities at the center city to decreasing return activities at the periphery (Schwarz, 2010). The first represents the exchanges 
between the ecosystem and the rest of the country. This represents logistic costs that may have a negative impact on pollution and carbon emission that may be reincorporated in the balance of the city to measure it smartness. The third is the external environment with witch the city exchanges, that is, in a age of a globalized world, the rest of the world: the larger this perimeter, the more the system is subject to external factors of instability and the less the ecosystem is coherent as a Thünen zone ${ }^{1}$.

c. Combining top down and bottom-up integration: Each industry has today its model for the integration of its activities. Smart grids, water suppliers, transport operators, IT providers ... have model for systemic integration of their subsystem and to evaluate its impact on the global functioning of the city. On the other hand, we know that the urban ecosystem being more than the sum of the subsystems we need another approach that starts from the top, that is from the strategic goals of the city deployed in functions as represented in figure 1.0. Where will be the meeting point of these two approaches? Proceeding bottom-up will raise problems of system interoperability, data syntax and semantics, while the top-down approach is more relevant to define strategic issues but will have to integrate all the existing businesses and functions. A possibility is that storing data in common data warehouses and completing it with the exploitation of big data will provide common references. In any case, the answer will proceed from applied research projects in building cities.

d. Defining new business models and competencies: Conceiving ecosystems needs the enterprises to cooperate to share a common strategic view so as to form a conception ecosystem based on the principle of "coopetition" (cooperation and competition). Each enterprise must define its performance indicators according to the performance of the whole and not only to that of its parts. The same concern is for public management: with the silo organization of public administration, no one is in charge of a global view of the city. This calls for new business models of enterprises extended not only to the partners of one enterprise but to the global value chain of the ecosystem. The same applies to public administration in its very organization to develop the competencies needed to deal with complex system design as well as its strategic thinking. The French public administration still consider its industrial strategy in terms of "filières" (channels) that are the vertical integration of similar activities (such as aerospace, automotive...), as it was relevant in the paradigm of mass production, while the locus of disruptive innovation is in the overlaps of different industries.

The French government was baffled when GE announced his intention to take over Alsthom. Would the French administration have understood the strategic issues at stake with smart cities as ecosystem and not only with the hard subsystems (water, sanitation, transportation...) where France has traditionally

\footnotetext{
${ }^{1}$ We may give as an example the city of Quimper at the heart of the granitic massif of Brittany (France) who choses to import its granite from China.
} 
strong positions, she would have valued differently the smart grid activity of Alsthom and its interest for competitors who aim to preempt the smart city market which value is estimated, for the sole so-called smart infrastructures, at 100 billion USD for the coming decade (Townsend 2013).

Another strategic issue is the battle for norms: a smart city is not, at the present time, defined with norms, metrics and metrology. Defining the norms (in terms of ISO standards) will allow lock-in the conception of smart cities by shaping all the tenders.

\section{Smart government, the keystone of smart cities}

Far as back as 1613, the Napolitano Antonio Serra, in a memoir presented at the viceking of Naples, analyzed the city as the place where activities with the biggest increasing returns take place, with a strong correlation between economics and politics (Reinert S., 2011). The frescoes of the Siena town hall by Ambroggio Lorenzetti depict "the good government" as a dynamic equilibrium between intense economic activities and an active political life that gives the people of citizens the power to rule the city according to the principles of the common good. Contemporary evolutionary economics correlates the evolution of institutions with that of economic activity (Reinert E. 2012).

The growing complexity of cities and the predominance of top-down urban planning have made us forgetful of these lessons from the past. In their analysis of present smart cities initiative, Neirotti \& a. (2013) notice that there is no practice that encompasses all the domains, hard and soft, of the cities. On the contrary, the most covered domains are hard ones: transportation and mobility, natural resources and energy. Government is the domain in which the cities report the lowest number of initiatives. More, there is an inverse correlation between investment in hard and soft domains, and smart government is still the poor relative in smart cities initiatives and cities that have invested in hard domains are not necessarily more livable cities. In fact, two models emerge form Neirotti \& a. survey: one focused on technology (with a strong impetus of technology vendors) and one focused on soft aspects, the hard model being dominant. The problem is there are no vendors for soft domains apart the citizens themselves whereas systemic integration relies on soft domains, mainly taking in account the context and valuing social capital.

Smart cities conceived as ecosystems should provide policy makers with some practical guidelines to integrate soft and hard domains. Three areas for smart government appear:

2 The total market of smart cities is estimated as much as $\$ 350$ trillion needed to build,
maintain, and operate the world's cities over the next forty years (WWF report "Reinventing the Cities", 2012) 
Economic development: In the past, smart cities have been built without central planning (except in the case of Roman cities which reflected the imperial objective of the Roman Empire) but with a clear, although not explicitly formulated, founding purpose: defense, commerce, religion, power, geography... The pattern of the city emerged out of the interactions of key stakeholders: The lord, the barons, the merchants, the shopkeepers, the craftsmen, the bankers and the people. The design of ancient cities made them intelligent since they were ecosystem that sustained and reinvented themselves along time... till the point their capacity to self-reinvent came to an end when the core of their strategic activity reached a tipping point (e.g Italian cities after the Renaissance, Russian monocities from the USSR era, Detroit today). The design of these cities obeyed to the real interactions underlying economic life (roads, markets, fairs, harbors, work, industry...) and civic activities (agora, city hall, structure of power). Their global ecosystem may be referred to as the ideal type conceptualized by J.H Thünen at the beginning of the XIX ${ }^{\circ}$ century, that is to say a center where the core of the city is with the strongest interactions and the returns are the highest, surrounded by concentric zones going of decreasing returns activities (Schwarz, 2010).

The task of government is to search for the activities that produce the highest increasing returns, no thanks to high technology but to synergies between activities (Reinert, 2012), that will constitute the center of the Thünen zones. The Russian monocities built on a unique industry (coal, oil, cars, aerospace....) linger as long as this industry has a leading role but have very poor capabilities to reinvent itself due to the lack of synergies between different economic activities.

A vibrant political life: With cities emerged political philosophy. The most perspicacious analyst of what makes a city great was undoubtedly Machiavelli who put emphasis on the necessity of the common good: "it is the common good and not private gain that makes cities great " he wrote in his Discourse on Livy. Machiavelli conceived the common good in the Thomas Aquinas' tradition as a whole superior to the sum of its parts. Its systemic equilibrium is permanently challenged by the corruptive forces of fortuna that must be offset by the virtù of the Prince and the dynamism of the vivere politico (Rochet, 2010). Emphasis has been put on the topicality of Machiavelli to understand the systemic character of public management (Rochet, 2009). The vitality of the system is sustained with permanent interactions within thanks to a vibrant political life that provide a space for controversies. Machiavelli praised the Roman republic for his institution of the tribunate that managed the confrontation between the many of the citizens and the few of the ruling class that allowed the Republic to upgrade his institutions according the principles of the common weal advocated by Cicero. The conservative French politician and historian François Guizot attributed the success of the European civilization to the permanence of the classes struggle as a means to build political compromises as a guarantee of sustainability, under the conditions that no class wins. In contemporary complex societies, Elinor and Vincent Oström have developed the concept of polycentric governance that is organizing governance on one hand on a vertical axis from upper to lower levels of complexities, and on the other hand on an horizontal axis which consists of overlappings between organizations (Östrom, 2010). Elinor and Vincent Ostrom have criticized the excess of rationality that defines strict boundaries 
within missions and attributions of public organizations, since the reality doesn't know these boundaries and the adaptive character of public systems may be found in their overlaps.

Supporting open innovation: In the contemporary smart cities, information technologies give more power than before to citizens to use and produce information, and also applications. The experience of cities opening their database to the public to trigger the development of apps has proved the payoff of bottom-up approaches: in Washington DC, a contest "apps for democracy" challenged the local developers to create software exploiting public resources. For a cost of 50000 US\$ the pay-off was blazingly fast with forty seven apps developed in thirty days, representing an estimated 2 million worth of services, about $4000 \%$ return on the city investment (Townsend 2013).

But one should not conclude that bottom-up approaches are the killing solution: theses apps are V 1.0 developed by techies on the basis of a fascination for technologies while the city needs V 7.0 tested and reliable and based on the real needs and problem solving of citizens as end-users not familiar with technology. We rediscover here one of the law of innovation emphasized by Von Hippel (1986): the key role of lead users in the innovation process which is furthermore not a specific aspect of innovation in the digital era but a permanent, although forgotten, feature of the innovation process in the industrial era as reminds us François Caron, a leading academic in history of innovation (Caron, 2012).

In the same manner national innovation systems exist (Freeman, 1995) and provide a framework that gives incentives to cooperation between industry, research and investors to steer their activities toward risk taking innovations, extended public administration could structure an urban innovation system that would structure the innovation process in a way that would guarantee that innovation, research and development of so-called smart apps are focused on the real needs of the city dwellers.

\section{Conclusion: Extended administration as art of systemic integration}

In the absence of a definition of how intelligent may be cities to be sustainable, today's initiatives are techno-pushed since tangible goods of the hard domains of smart cities drive the market. Digital economy seems to be the keystone of smart cities, but we have shown that the keystone in last resort is the end-users of technologies: the citizens. This requires a combination between soft and hard domains that can be achieved through complex systems architecture (Godfrey, 2012), a new discipline, methodology and competency in public management that we coin as urban lifecycle management $\mathbb{C}$.

Although according to system theory self-regulating systems exist - but once their genetic codes have been written - as they exist in nature and in small-scale human system such as those studied by Elinor Östrom for the management of the commons (Östrom, 1991), large complex systems such as smart cities need to be framed by a 
central architect before reaching its resilient and sustainable stage. The newborn concept of extended administration finds here its application in its intention to encompass and to design the global value chain of public administration and its interaction with - and between - all the stakeholders. This implies a sea change in the competencies and business model of public administration. This new field would be carried out through research in action projects building cities as ecosystem tending toward resilience where humans are first to decide for the ends.

\section{References:}

- Alexander, C. (1977) "A pattern language, town, buildings, constructions", with Sarah Ishikawa et Murray Silverstein, Oxford University Press

- Ashby W.R. (1962): "Principles of the Self-organizing System", in:Principles of Self-Organization, von Foerster H. \& Zopf G.(eds.),(Pergamon, Oxford), Cambridge, MA, 193-229.

- Aydalot Ph. Ed., “Milieux Innovateurs en Europe”, GREMI, Paris, 1986.

- Caron, François (2012) «La dynamique de l'innovation », Albin Michel, Paris

- Dedijer, Stephan, 1984 «Au-delà de l'informatique, l'intelligence sociale », Stock, Paris

- Freeman, C. (1995a), 'The national system of innovation in historical perspective', in Cambridge Journal of Economics, vol. 19, no. 1.

- Godfrey, Patrick, «Architecting Complex Systems in New Domains and Problems: Making Sense of Complexity and Managing the Unintended Consequences » in Complex System and Design Management, Proceedings, 2012.

- Hardin, G., The Tragedy of the Commons, Science, New Series, vol. 162, $n^{\circ} 3859$ (dec. 13, 1968), pp. 1243-1248.

- Howard, E, 1902, "Garden Cities of To-morrow" (2nd ed.), London: S. Sonnenschein \& Co

- Jacobs, Janes, 1985 «Cities and the Wealth of Nations », Random House, NewYork.

- Krob Daniel, Eléments d'architecture des systèmes complexes, [in "Gestion de la complexité et de l'information dans les grands systèmes critiques", A. Appriou, Ed.], 179-207, CNRS Editions, 2009.

- Lizaroiu G.C, Roscia M. 2012 «Definition methodology for the smart cities model »

- Neirotti P., De Marco A, Corinna Cagliano A, Mangano G, Scorrano F, "Current trends in Smart City initiatives: Some stylised facts" Cities, Volume 38, June 2014, Pages 25-36 
- Ostrom, Elinor, 1991 «Governing the Commons ; The Evolution of Institutions for Collective Action » Cambridge University Press, NY.

- Ostrom, Elinor, 2010 "Beyond Markets and States: Polycentric Governance of Complex Economic Systems" American Economic Review, 1-33.

- Reinert, Sophus A., ed. Antonia Serra, "A Short Treatise on the Wealth and Poverty of Nations (1613)". Anthem Press, London 2011.

- Rochet, Claude, 2008 Le bien commun comme main invisible: le legs de Machiavel à la gestion publique, Revue Internationale des Sciences Administratives, 2008/3 (Vol. 74)

- Rochet, Claude, 2011 “Qu'est-ce qu'une bonne décision publique "? Editions universitaires européennes

- Schwartz, Herman, 2010, «States vs Markets: The Emergence of a Global Economy », Palgrave 3rd ed.

- Simon, H. A., 1969, « The Sciences of the Artificial », MIT Press, 3rd ed. 1996.

- Tainter, J. 1990 "The collapse of Complex Societies” Cambridge University Press.

- Von Hippel, E., 1986, "Lead Users: A Source of Novel Product Concepts", Management Science, 32(7): 791-806,

- West, Geofrey, Luís M. A. Bettencourt, José Lobo, Dirk Helbing, Christian Kühnert «Growth, innovation, scaling, and the pace of life in cities » Indiana University, 2007. 